\title{
Configurações
}

Revista de sociologia

$25 \mid 2020$

Debater o desenvolvimento: questões, dilemas e alternativas

\section{Ficha Técnica}

\section{Direção da Revista Configurações}

\section{(2) OpenEdition \\ 12 Journals}

\section{Edição electrónica}

URL: http://journals.openedition.org/configuracoes/7853

DOI: 10.4000/configuracoes.7853

ISSN: 2182-7419

Editora

Centro de Investigação em Ciências Sociais

\section{Edição impressa}

Paginação: 2-3

ISSN: 1646-5075

\section{Refêrencia eletrónica}

Direção da Revista Configurações, « Ficha Técnica », Configurações [Online], 25 | 2020, posto online no dia 12 junho 2020, consultado o 23 junho 2020. URL : http://journals.openedition.org/configuracoes/ 7853 ; DOI : https://doi.org/10.4000/configuracoes.7853

Este documento foi criado de forma automática no dia 23 junho 2020.

(c) CICS 


\title{
Ficha Técnica
}

\author{
Direção da Revista Configurações
}

Título: CONFIGURAÇÕES 25 / JUNHO DE 2020

2 Diretora: Ana Maria Brandão

3 Conselho Consultivo: Ana Nunes de Almeida (Univ. Lisboa), António Colomer (Univ. Polit.. Valência), António Lucas Marín (Univ. Complutense), Carlos Alberto da Silva (Univ. Évora), Claude-Michel Loriaux (Univ. Católica de Lovaina), Daniel Bertaux (CNRS, Paris), Elísio Estanque (Univ. Coimbra), François Dubet (Univ. Bordéus), Ilona Kovács (Univ. Téc. de Lisboa), James R. Taylor (Univ. Montreal), João Arriscado Nunes (Univ. Coimbra), João Ferreira de Almeida (ISCTE-IUL, Lisboa), João Teixeira Lopes (Univ. Porto), John Law (Univ. Lancaster), José Bragança de Miranda (Univ. Nova Lisboa), José Carlos Venâncio (Univ. Beira Interior), José Madureira Pinto (Univ. Porto), José Manuel Sobral (Univ. Lisboa), José Maria Carvalho Ferreira (Univ. Téc. Lisboa), Loïc Wacquant (Univ. Califórnia, Berkeley), Luís Baptista (Univ. Nova Lisboa), Maria Beatriz Rocha Trindade (Univ. Aberta), Manuel Villaverde Cabral (Univ. Lisboa), Manuela Ribeiro (Univ. Trás-os-Montes e Alto Douro), Michel Maffesoli (Univ. Paris V, Sorbonne), Ramón Máiz (Univ. Santiago de Compostela), Renato Lessa (Univ. Fluminense), Veit Bader (Univ. Amesterdão)

4 Conselho Científico: Ana Maria Brandão (UM), Ana Paula Marques (UM), António Cardoso (Inst. Polit. Viana do Castelo), Catarina Tomás (Instit. Polit. Lisboa), Dina Peixoto (ISCET-Porto), Domingos Santos (Inst. Polit. Castelo Branco), João Carvalho (ISMAI), José Fernando Bessa Ribeiro (UTAD), José Lopes Cordeiro (UM), Manuel Carlos Silva (UM), Maria Cristina Moreira (UM), Maria João Simões (UBI), Maria Johanna Schouten (UBI), Maria Paula Mascarenhas (UM), Rodrigo da Costa Dominguez (CICSUM), Sheila Khan (CICS-UM), Sílvia Gomes (ISMAI, CICS-UM), Teresa Mora (UM), Vera Duarte (ISMAI)

5 Edição: Rita Moreira (cics@ics.uminho.pt) e Iolanda Fontainhas (configuracoes_cics@ics.uminho.pt)

6 Propriedade, redação e administração: Centro Interdisciplinar de Ciências Sociais Polo da Universidade do Minho, 4710-057 Braga - Portugal. Telef.: 253601 752. Fax: 253 
604 696. Site: https://www.cics.nova.fcsh.unl.pt/polos/cics-nova-uminho e http:// cics.uminho.pt/?lang=pt"

7 Coordenadores deste número: Fernando Bessa Ribeiro, Ivonaldo Leite e Joel Felizes

8 Normas para apresentação e avaliação de artigos: Apresentação de originais: os textos propostos para publicação devem seguir as normas sugeridas no site da revista configurações https://configuracoes.revues. org/84

9 Avaliação de artigos: os artigos propostos são submetidos a parecer de especialistas das áreas respetivas, em regime de anonimato. A listagem de avaliadores será publicada cumulativamente a cada dois anos. A decisão final cabe à equipa coordenadora de cada número e, em última instância, à Direção do Centro Interdisciplinar de Ciências Sociais - Polo da Universidade do Minho

Os textos podem ser publicados em português, espanhol, francês e inglês Interdisciplinar de Ciências Sociais - Polo da Universidade do Minho, 4710-057 Braga

13 Capa: Furtacores design; fotografia da capa: Abigail Ascenso

14 ISSN: $1646-5075$

Depósito legal n..: 246289/06

Esta revista prossegue a série de Sociologia (6 números) de Sociedade e Cultura da revista Cadernos do Noroeste 